\title{
A suitable waiting room? Hospital transfer outcomes and delays from two London prisons
}

\section{AIMS AND METHOD}

To describe a group of prisoners who required transfer to mental health units from two London prisons. Data were collected from prison clinical records.

\section{RESULTS}

Overall, 149 patient-prisoners were

\author{
transferred over a 17-month period. \\ Around a quarter were not previously \\ known to services. The aggregate \\ wait was 36.5 years (averaging \\ between 93 and 102 days per \\ prisoner) and the total saving to the \\ National Health Service (NHS) has \\ been estimated at $f 6.759$ million.
}

\author{
CLINICAL IMPLICATIONS \\ Both prisons manage a large \\ number of prisoners with untreated \\ psychosis. While in prison, they save \\ the NHS considerable sums of money, \\ but transfer delays prevent timely \\ treatment and could now be legally \\ challenged.
}

There is extensive international evidence of the substantial burden of severe mental illness in prisoners. For example, in a study of 16 prisons and institutions for young offenders in the UK, Brooke et al found that $5 \%$ of the remand population had a psychotic or affective disorder. ${ }^{1}$ In a systematic review of 62 surveys based on interviews of unselected prison populations in Europe, Australia, New Zealand, Canada and the USA, Fazel \& Danesh found consistent evidence that prisoners were several times more likely to have psychosis or major depression than the general population. They also found that comorbidity between mental illness, substance misuse and personality disorder was the norm, rather than the exception. ${ }^{2}$

Harty et al used systemic needs assessment instruments to demonstrate that mentally disordered prisoners at London's HM Prison Belmarsh differed from general adult patients living in the community: they had significantly more needs, and more unmet needs, in relation to mental health. Their unmet needs were in the domains of psychotic symptoms, psychological distress, company and daytime activities. ${ }^{3}$

Although there have been considerable improvements in mental health services for prisoners in the UK over the past decade, prison healthcare centres do not provide equivalent healthcare to that available in in-patient units, ${ }^{4}$ nor are they recognised as places where compulsory treatment can be given under the provisions of the Mental Health Act. Mental health teams in prison expect to be able to support prisoners with stable mental illness during a period in custody, but require support from local mental health providers for the provision of in-patient care when necessary.

The care pathway for prisoners requiring in-patient treatment is fraught with difficulties and most prison healthcare centres in London are used to accommodate prisoners at various stages of the transfer process. They have therefore become, for large numbers of prisonerpatients, waiting rooms for hospital admission.

In recognition of this problem, the Department of Health produced an invitation to pilot a national waiting time standard for the transfer of acutely mentally ill prisoners, ${ }^{5}$ and published practice guidelines in which an ambitious 7-day target for transfer to hospital was set (later amended to 14 days). ${ }^{6}$ This invitation has since been taken up by a number of National Health Service (NHS) providers within the London area, and an outcome is awaited.

\section{Method}

\section{Data collection}

The London prison estate contains seven prisons (including one prison for women, HM Prison Holloway, and one young offender institution, HM Prison and Young Offender Institution Feltham) and has an overall capacity of just under 7000. This study involved two central London prisons with differing functions: HM Prison Brixton and HM Prison Belmarsh.

HM Prison Brixton is one of the oldest correctional facilities in the UK, dating from 1819. It presently functions as a category $B$, or medium secure, local remand prison. Serving a variety of local courts, it has an operational capacity of almost 800. HM Prison Belmarsh became operational in 1991 and has an operational capacity of just over 900 . It also serves local courts but has an additional function as a high secure prison involving the detention of category A prisoners.

Prospective audit data were collected from clinical records at both prisons for all prisoners transferred to psychiatric facilities under Part III of the Mental Health Act 1983 during the period 1 June 2003 to 31 October 2004 (a total of 17 months). Prison transfer records were cross-checked to ensure accuracy and entered into a referral database (set up as an Excel spreadsheet). The collected data comprised referral, assessment, acceptance and transfer times, along with the level of security of the accepting unit and the section of the Mental Health Act used.

For the purpose of this study, the transfer period began when a referral was made by the prison's mental health service to a receiving unit and continued until the date when actual transfer took place. Although this system was not the same as the prison service's 'traffic 
lights' measuring system, which measured transfer time from date of acceptance rather than date of referral, it

original papers provided a more accurate account of waiting times.

\section{Results}

There were a total of 149 transfers from both prisons to NHS mental health facilities during the 17 months under examination (just under nine transfers per month): 92 from Brixton and 57 from Belmarsh (four individuals were excluded from the study because their medical records could not be located). During the same period, six of those transferred to hospital were remitted to prison under section 50 of the Mental Health Act. Two of those remitted required immediate re-referral and re-admission.

Of those transferred from Brixton, $60 \%$ were charged with, or had committed, some form of violent offence (including grievous bodily harm, actual bodily harm, assault or common assault). Of those transferred from Belmarsh, $73 \%$ were detained in respect of a violent offence (of which over $50 \%$ included murder, attempted murder or manslaughter). The offence spread was therefore more serious at HM Prison Belmarsh, as might be expected from its category A function.

Although the majority of those transferred from both prisons were already known to mental health services (74\% at $\mathrm{HM}$ Prison Brixton and 75\% at $\mathrm{HM}$ Prison Belmarsh), a substantial number from both groups (25\%) had no history of contact (being provided with services for the first time within the prison system). The past psychiatric history of four prisoners was not known.

The majority of prisoners were transferred to one of four different levels of security within NHS hospitals and a small number were transferred to facilities with a specialist function (e.g. learning disability services). The levels of security involved were:

- general adult wards

- psychiatric intensive care units

- medium secure units

- high-security hospitals.

The transfer details are quantified in Table 1.

\section{Legal provisions}

Part III of the Mental Health Act 1983 allows for a number of sections to be used to facilitate prisoner transfer to mental health facilities. Of the sections available for use, the following were the most relevant:

- section 48 (allowing the clinical transfer of remand prisoners without court involvement)

- section 47 (allowing the clinical transfer of sentenced prisoners without court involvement)

- section 49 (restricting the discharge of prisoners transferred to hospital)

- section 35 (a remand order issued by the court)

- section 37 (a hospital order issued by the court)

- section 38 (an interim hospital order, allowing a period of evaluation in hospital before definitive disposal).
Of the main Mental Health Act sections used, sections 47 and 48 were administered by the mental health department at the Home Office (now the Ministry of Justice), all such prisoners receiving a parallel order restricting their discharge under section 49 . The remainder came under the determination of the courts (with the option of adding a restriction order under section 41 of the Mental Health Act to those whose cases were finally disposed of via a hospital order under section 37). Results are presented in Table 2.

\section{Waiting time}

The 92 mentally disordered prisoners at HM Prison Brixton waited, in aggregate, some 22 years (8428 days) in prison for a hospital bed over the 17 months of the study. The average wait per prisoner was 102 days. Of those transferred, only 20\% were referred, assessed and transferred within 1 month, 38\% were transferred within 3 months, $42 \%$ waited longer than 3 months and a further $10 \%$ waited longer than 6 months.

Meanwhile, the 57 mentally disordered prisoners at HM Prison Belmarsh waited, in aggregate, some 14.5 years (5285 days) for a hospital bed, with an average wait per prisoner of 93 days. Of those, $21 \%$ were referred, assessed and transferred within 1 month and $37 \%$ within 3 months. In keeping with the figures from Brixton, $42 \%$ waited longer than 3 months for a hospital bed and the remaining 10\% waited in excess of 6 months.

Based on unit costs, ${ }^{7}$ we estimate the total saving to the NHS for both prisons over the period under examination at $£ 6757644$. Costs have been calculated for prisoners transferred under all Mental Health Act orders, not merely the 'urgent' sections, as in our experience court orders often simply expedite the transfer process

Table 1. Facilities where the prisoners were transferred, by the level of security

\begin{tabular}{|lcc}
\hline Facility & $\begin{array}{c}\text { HM Prison } \\
\text { Brixton, \% }\end{array}$ & $\begin{array}{c}\text { HM Prison } \\
\text { Belmarsh, \% }\end{array}$ \\
\hline General adult ward & 8 & 3 \\
Psychiatric intensive care unit & 54 & 23 \\
Medium secure unit & 34 & 54 \\
High secure unit & 1 & 19 \\
Specialist facility & 3 & 2 \\
\hline
\end{tabular}

Table 2. Mental Health Act sections used to facilitate prisoners' transfer to mental health services

\begin{tabular}{|lcc}
\hline Mental Health Act section & $\begin{array}{c}\text { HM Prison } \\
\text { Brixton, \% }\end{array}$ & $\begin{array}{c}\text { HM Prison } \\
\text { Belmarsh, \% }\end{array}$ \\
\hline Section 48 & 49 & 63 \\
Section 47 & 23 & 12 \\
Section 37 (with section 41) & $20^{\mathrm{a}}$ & $12^{\mathrm{b}}$ \\
Section 38 & 6 & 8 \\
Section 35 & 2 & 5 \\
\hline
\end{tabular}

a. Fifty-eight per cent received additional restriction orders under section 41 .

b. All received additional restriction orders under section 41 . 
Savings, $\mathrm{f}$

\begin{tabular}{lcrrr} 
& $\begin{array}{c}\text { Unit cost per patient } \\
\text { Transfer facility }\end{array}$ & HM Prison Belmarsh & HM Prison Brixton & Total \\
\cline { 3 - 4 } General adult ward & 258 & 40906 & 173954 \\
Psychiatric intensive care unit & 542 & 658828 & 2466707 & 3125535 \\
Medium secure unit/specialist facility & 453 & 1340699 & 1412618 \\
Maximum secure hospital & 610 & 612531 & 51411 & 663942 \\
\end{tabular}

for individuals who have already been referred on an urgent basis. A breakdown of costs and savings is given in Table 3.

\section{Discussion}

\section{NHS and prison service align}

The way in which mental healthcare is provided for prisoners in England and Wales has changed substantially over the past decade, since serious problems with earlier provision (including poor quality care and professional isolation) were identified by HM Chief Inspector of Prisons in $1996 .{ }^{8}$ Before then, visiting psychiatrists received referrals from resident prison medical officers and service provision was patchily available. In an attempt to solve the problems, mental health in-reach services, intended to be similar in design to community mental health teams, were introduced to the prison estate in 2001. More recently, local primary care trusts have taken responsibility for commissioning services (full primary care trust commissioning came online in 2006).

With this new formal relationship between the prison service and the NHS has come a new form of scrutiny. By virtue of its new location inside the walls of the prison, the NHS becomes increasingly responsible for the healthcare needs of prisoners and for monitoring whether those needs are, or are not, being met.

\section{London's recent transfer history}

Earlier research at HM Prison Brixton has described frustration, difficulties and delays with the referral and assessment process. In the early 1990s, an average 5- to 6 -week delay between a prisoner being offered a bed and being admitted to hospital was standard. ${ }^{9}$ Although a later study into the effectiveness of a psychiatric diversion scheme from HM Prison Belmarsh suggested some cause for optimism, ${ }^{10}$ a subsequent audit identified lengthy delays before a hospital bed was found..$^{11}$ Multiple problems were identified in the second audit, including differences in opinion, legal disputes, diagnostic disagreements, long delays before initial assessments and NHS catchment area disputes.

More recently, in recognition of the problem, the Department of Health has produced new administrative procedures to reduce delays. ${ }^{6}$ These procedures, designed to ensure that the commissioning primary care trusts are aware of their financial responsibilities at an early stage, have since been cascaded through the prison estate. One London prison (HM Prison Pentonville) has described a subsequent reduction in transfer waiting times. ${ }^{12}$ However, the significance of these results for the wider prison estate remains uncertain. Reductions in waiting times have apparently been minimal (from 77 to 53 days), remaining far short of the Department of Health's target, as the 7-day target has since been replaced by a 14-day target. This seems to indicate that that problem has, if anything, become worse since the early 1990 s.

\section{Implications}

We remain concerned about the transfer delays described in this paper. We are particularly concerned about those who wait untreated in prison, without the protection of the Mental Health Act, for whom the only recourse to treatment used to be Common Law but may now involve the Mental Capacity Act 2005.13 Although we do not yet know the numbers involved, many are unable to make decisions for themselves because they lack capacity. The Mental Capacity Act 2005 requires individuals and services to act in the best interests of such individuals; delaying hospital admission does not meet this aim. In the case of Jean-Luc Riviere v. France, the European Court of Human Rights ruled that Riviere's continued detention in prison when he required treatment for mental illness contravened his Article 3 right to freedom from inhuman and degrading treatment. ${ }^{14}$ We therefore think that the delays described in this paper could be subject to legal challenge.

\section{Declaration of interest}

None.

\section{References}

1 Brooke D, Taylor C, Gunn J, Maden A. Point prevalence of mental disorder in unconvicted male prisoners in England and Wales. BMJ 1996; 313: 1524-7.

2 Fazel S, Danesh J. Serious mental disorder in 23000 prisoners: a systematic review of 62 surveys. Lancet 2002; 360: 572-3.

3 Harty M, TightJ, Reese M, Parrott J, Thornicroft $\mathrm{G}$. Inverse care for mentally ill prisoners: unmet needs in forensic mental health services. J Forensic Psychiatry Psychol 2003; 14: $600-15$. original papers 


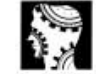

original papers
7 Department of Health. National Schedule of Reference Costs 2006-2007 for NHS Trusts. Department of Health, 2007.

8 HM Inspectorate of Prisons. Patient or Prisoner? A New Strategy for Healthcare in Prisons. Home Office, 1996.

9 Robertson G, Dell S, James K, Grounds A. Psychotic men remanded in custody to Brixton Prison. $\mathrm{Br}$. Psychiatry 1994; 164: 55-61.

10 Banerjee S, O'Neill-Byrne K, ExworthyT, ParrottJ. The Belmarsh
Scheme. A prospective study of the transfer of mentally disordered remand prisoners from prison to psychiatric units. BrJ Psychiatry 1995; 166: 802-5.

11 Isherwood S, Parrott J. Audit of transfers under the Mental Health Act from prison - the impact of organisational change. Psychiatr Bull 2002; 26: 368-70.

12 McKenzie N, Sales B. New procedures to cut delays in transfer of mentally ill prisoners to hospital. Psychiatr Bull 2008: 32: 20-2.
13 Wilson S, Forrester A. Too little, too late? The treatment of mentally incapacitated prisoners. J Forensic

14 Riviere v. France (2006) ECHR Application no. 33834/03, 11 July.

Psychiatry 2002: 13:1-8.

*Andrew Forrester Consultant and Honorary Senior Lecturer in Forensic Psychiatry, Healthcare Department, HM Prison Brixton, Jebb Avenue, London SW2 5XF, email: andrew.forrester@ slam.nhs.uk, Christopher Henderson Formerly Research Associate, Bracton Centre Medium Secure Unit, Bexley, Simon Wilson Consultant and Honorary Senior Lecturer in Forensic Psychiatry, Oxleas NHS Foundation Trust and Institute of Psychiatry, London, lan Cumming Consultant in Forensic Psychiatry, HM Prison Belmarsh, London, Miriam Spyrou Assistant Psychologist, Bracton Centre Medium Secure Unit, Bexley, Janet Parrott Consultant in Forensic Psychiatry, Bracton Centre Medium Secure Unit, Bexley

\section{How specialist ECT consultants inform patients about memory loss}

\section{AIMS AND METHOD}

A questionnaire was distributed to consultants with a special interest in electroconvulsive therapy (ECT) at clinics participating in an ECT accreditation process. This aimed to ascertain a consensus of clinical practice regarding informing patients about the treatment and assessment of memory during ECT.

\section{RESULTS}

The response rate was $64 \%$. There is consensus on informing patients about the possibility of permanent memory loss. Memory is assessed before and during an ECT course by clinical interview and Mini-Mental State Examination, but rarely at longterm follow-up.

\begin{abstract}
CLINICAL IMPLICATIONS
Patients need to be informed about the possibility of permanent memory loss before consenting to ECT. Clinical teams need to make greater efforts to assess memory, particularly after this treatment.
\end{abstract}

Electroconvulsive therapy (ECT) is an effective short-term treatment for depression and is 'probably more effective than drug therapy'. However, the treatment remains controversial, with adverse effects being a major concern of both patients and the public, in particular the risk of memory impairment. A review of patients' perspectives on ECT found that at least a third of patients reported persistent memory loss after treatment. ${ }^{2}$

Research into the effect of ECT on memory function is a rapidly changing field. Previously, it was accepted that this treatment could cause temporary anterograde and retrograde amnesia, which could be minimised by using unilateral rather than bilateral ECT; ${ }^{3}$ however, current work is clarifying the possibility and nature of more persistent memory loss. A recent systematic review suggested that autobiographical memory impairment after ECT can occur, recovering after several months, although a few studies reported more persistent deficits. ${ }^{4}$ A large prospective study found that cognitive deficits, including deficits in autobiographical memory, were apparent 6 months after completion of a course of $\mathrm{ECT}^{5}$

There is concern that inadequate information is given to patients about the adverse effects of ECT, specifically with regard to the effect on memory. ${ }^{6,7}$ The ECT Accreditation Service (ECTAS) has previously studied the clinical practice and training needs of psychiatrists who refer patients for ECT. These referring psychiatrists were likely to have difficulty explaining to patients the possibility of long-term cognitive side-effects, with a spread of opinion among them, ranging from informing patients about long-term cognitive side-effects, to saying that there was no evidence of such side-effects, or saying that the issue is controversial. Just over a third recognised further training needs, particularly on consent and assessment of memory during and after ECT. ${ }^{8}$ There has been a gradual decline from 1985 to 2002 in the number of people in England receiving ECT, ${ }^{9}$ and it is likely that this trend has continued. Thus referring psychiatrists will have less experience of this treatment.

The aim of our study was to gain a greater understanding of the clinical practice of psychiatrists with responsibility for administration of ECT in the UK (ECT specialists or lead ECT clinicians, hereafter referred to as ECT consultant psychiatrists), with specific reference to what they tell patients about the effects of ECT on memory and how they approach detecting and monitoring these effects. This was in order to obtain a consensus of expert opinion in this area.

\section{Method}

The ECTAS was established in 2003 to improve the quality of ECT provision in England, Wales, Northern Ireland and Ireland. Clinics judged to provide a 